\title{
Accuracy and the factors influencing the accuracy of death certificates completed by first-year general practitioners in Thailand
}

Chaiwat Washirasaksiri ${ }^{1}$, Prateep Raksasagulwong ${ }^{2}$, Charoen Chouriyagune ${ }^{1}$, Pochamana Phisalprapa ${ }^{1}$ and Weerachai Srivanichakorn ${ }^{1 *}$ (i)

\begin{abstract}
Background: Although death certificates (DCs) provide valuable health information which may help to guide local health policies and priorities, there is little information concerning their validity in Thailand. First-year general practitioners (GPs) have a major role in DC completion, especially in provincial general hospitals. The aim of this study was to evaluate the accuracy and factors influencing the accuracy of DCs completed by first-year GPs in Thailand, compared with the cause of death (COD) derived from medical records by experts.

Methods: This retrospective study was conducted at 14 provincial general hospitals in Thailand during the June 2011 to May 2012 study period. Medical records and DCs completed by first-year GPs who graduated from 16 Thai medical schools were sampled. The cause of death recorded on the DCs was compared with the medical conditions and histories derived from patient medical records. A cross-sectional survey of the 210 GPs who completed the DCs reviewed in this study was also conducted. Respondent GPs' demographic characteristics, factors associated with COD, and COD coding system were evaluated.

Results: Five hundred and sixty-three medical records and corresponding DCs were included. Of those, 36.9\% of DCs were found to be correct. Common mistakes included incorrect sequence of events leading to death (32.4\%), and mode of death use (26.2\%). Of the $210 \mathrm{GPs}, 155$ questionnaires were completed and returned. The mean time spent on recording COD and completing DCs in the medical school curriculum was $2.1 \pm 0.9 \mathrm{~h}$ and only $27.7 \%$ of participants had experience in completing DCs by themselves during medical school. Mean medical school GPA was significantly higher in the correctly completed DC GPs group than in the incorrectly completed DC GPs group (3.3 \pm 0.4 vs. $3.2 \pm 0.3 ; p=0.03$ ). However, no significant difference was found for other factors associated with COD between groups.

Conclusions: This is the first study documenting gaps and disparities in DC accuracy, and factors influencing completion of DCs among first-year GPs in Thailand, based on a clinical assessment of medical records. GPs made errors on $63.1 \%$ of DCs. This finding suggests that proven education, system-related support, and additional training interventions specific to DC completion are required.
\end{abstract}

Keywords: Thailand, Death certificate, General practitioner, GP, Quality, Influencing factors

\footnotetext{
* Correspondence: weerachai.srv@mahidol.ac.th

${ }^{1}$ Division of Ambulatory Medicine, Department of Medicine, Faculty of

Medicine Siriraj Hospital, Mahidol University, 2 Wanglang Road, Bangkoknoi,

Bangkok 10700, Thailand

Full list of author information is available at the end of the article
}

(c) The Author(s). 2018 Open Access This article is distributed under the terms of the Creative Commons Attribution 4.0 International License (http://creativecommons.org/licenses/by/4.0/), which permits unrestricted use, distribution, and

reproduction in any medium, provided you give appropriate credit to the original author(s) and the source, provide a link to the Creative Commons license, and indicate if changes were made. The Creative Commons Public Domain Dedication waiver (http://creativecommons.org/publicdomain/zero/1.0/) applies to the data made available in this article, unless otherwise stated. 


\section{Background}

Death certificates (DCs) provide valuable national health information regarding population-based mortality, disease incidence, and disease prevalence - particularly in some preventable diseases. This information may lead to the development and implementation of local health policy, and help to guide resource prioritization and management [1]. DCs provide valuable data for health researchers and epidemiological studies, and also benefit families by providing data about risk factors for inherited diseases. Although DCs are an important tool for reporting and gathering vital statistics within a population, there is little evidence concerning their validity and the factors that influence their accuracy [1-4]. Death certificate (DC) errors contribute to unreliable results in population-based studies and inaccurate public health policy trends [5]. Previous reviews have demonstrated that DC completion errors are common [6-9], ranging from 25.0 to $78.0 \%$ in a hospital-based study $[7,8]$. In terms of a gold standard, there have been different approaches to assessing DC accuracy, including autopsy data, verbal autopsy, and the use of medical records [10-14].

A previous study [15] reported that recent mortality statistics in Thailand were of low quality, with over $30.0 \%$ of deaths unregistered and more than $20.0 \%$ of underlying causes of death (COD) classified as "ill-defined cause". In Thailand, first-year general practitioners (GPs) have a major role in DC completion, especially in provincial general hospitals. Although this is a multi-factorial problem [16], one of the possible explanations is that some physicians may not receive sufficient training and support in DC completion, and this may result in inaccurate in the completion and recording of inaccurate DCs [17]. The aim of this study was to investigate the accuracy of DCs, and to identify patterns and characteristics of DC errors. Physician-related factors, such as demographics, knowledge, experience, DC education, support systems, and other possible factors that may influence DC completion, were also evaluated.

\section{Methods}

This retrospective study was conducted at 14 provincial general hospitals in Thailand during the June 2011 to May 2012 study period. First-year general practitioners who graduated from 16 public medicals school registered with the Medical Council of Thailand in 2011 were randomly selected to receive questionnaires. These 16 medical schools produce approximately 2000 medical graduates each year. Medical graduates from private and unregistered medical schools were excluded. A total of 210 first-year general practitioners from 16 medical schools were randomly selected from 14 of 50 (28.0\%) provincial general hospitals from all regions of Thailand. Approximately $10.0 \%$ of the total number of GPs from each medical school was included in this study. Included GPs had to have a minimum of 3 charts and 3 associated DCs. The quality of the charts was assessed and incomplete medical records were excluded. A cross-sectional questionnaire was distributed to randomly selected physicians to explore factors, such as knowledge about DCs, education, workload, and experience in completing DCs.

The DC forms used to report the underlying COD in Thai hospitals follow World Health Organization guidelines [18]. Information is recorded in a three-part format. The sequence of events leading to the COD are recorded in part one. Part two is used to record other significant conditions contributing to death. Part three, which is only used in Thai DCs, is a section translated into Thai. The COD is defined as the disease or injury that initiated the train of morbid events directly leading to death, or the circumstances of the accident or violence that produced the fatal injury. The COD is recorded on the last line of part one. The present study evaluated the recorded COD and translation section of all included DCs. The accuracy of this information was corroborated and validated by reviewing the relevant information in the corresponding medical records. The initial evaluation was conducted by one trained doctor and one auditor. In case of discrepancies, a third expert made an independent judgment, with final agreement reached via consensus. Correct COD was defined as both selected parts of the DC being correct according to the judgement of the reviewers. Participants who coded an appropriate COD in more than $60 \%$ of the DCs they completed were classified as the "correct DC GP group", with the remaining participants classified as the "incorrect DC GP group." Common mistakes on the death certificate were classified and defined as follows: 1) Incorrect sequence of events leading to death - an incorrect temporal ordering of information in the part 1 cascade; 2) Mode of death use - an incorrect selection of the manner of death, such as respiratory failure or cardiac arrest, in the part 1 cascade; 3) Nonspecific cause of death - giving a generic cause of death (e.g., sepsis), which, though a disease process, was then not followed-up with an underlying cause of death; 4) Linkage errors - selecting a cause of death that is linked by a provision in the classification; 5 ) Incorrect $C O D$ recorded in the comorbidity section that is transposed from part 1 (the cause of death) to part 2 (contributory conditions) or vice versa; 6) Incomplete diagnosis or no COD on the DC; 7) Errors in Thai translation; and, 8) Trivial condition- the selected cause is a minor condition unlikely to cause death.

Clinical parameters associated with DC accuracy, including physician-specific factors and COD coding systems were collected. Data collected by questionnaire included demographic characteristics (age, gender, medical school grade point average [GPA], workload, hospital 
at which the participant works, education, and future career/medical specialization plans); factors associated with COD accuracy (DC knowledge, confidence in completing DCs, and factors influencing errors); and COD coding systems (training in COD coding, responsible person).

\section{Sample size calculation and statistical analysis}

The proportion of general internal medical residents completing correct death certificates was found to be $65.0 \%$ from a previous survey conducted at the Department of Medicine, Faculty of Medicine Siriraj Hospital. The estimate of the proportion of the population by setting the relative error tolerance was $10 \%$ of the proportion of medical graduates completing correct death certificates at 95\% confidence level. The calculation of the sample size used in this study, approximately 210 first-year general physicians should be recruited. The minimum of 3 charts and 3 associated DCs per each physician were required for evaluation. Therefore, 630 charts and associated DCs were recruited in this present study.

Completed questionnaires, DCs, and medical records were assessed. Categorical data are presented as frequencies and percentages. Categorical data, such as factors associated with the accuracy of COD, were compared using chi-square test or Fisher's exact test if the element was an enumeration data point. Continuous data are expressed as mean \pm standard deviation (SD), with $t$-test used to compare differences between groups. Odds ratios of parameters of accuracy of DC completion between the correct and incorrect DC groups and odds ratios of each disease in correctly completed DCs were assessed using univariate logistic regression analysis. All statistical analyses were

Table 1 Death certificate and medical record data among groups

\begin{tabular}{|c|c|c|c|}
\hline Death certificate characteristics & All DCs $(n=563)$ & Correct DCs $(n=208)$ & Incorrect DCs $(n=355)$ \\
\hline 1. Age $(\mathrm{yr})$, mean $\pm S D$ & $58.0 \pm 21.5$ & $60.2 \pm 20.6$ & $56.7 \pm 22.0$ \\
\hline 2. Female gender: $n(\%)$ & $207(45.7)$ & $84(47.5)$ & $123(44.6)$ \\
\hline 3. Evaluation of events leading directly to COD, $n(\%)$ & $563(100)$ & $321(57.0)$ & $242(43.0)$ \\
\hline 4. Thai COD coding evaluation, $n(\%)$ & $563(100)$ & $229(40.7)$ & $333(59.3)$ \\
\hline \multicolumn{4}{|l|}{ 5. Hospital size: $n(\%)$} \\
\hline - > 1000 beds & $118(21.0)$ & $43(20.7)$ & $75(21.1)$ \\
\hline • 701-1000 beds & $160(28.4)$ & $67(32.2)$ & $93(26.2)$ \\
\hline - 401-700 beds & $285(50.6)$ & $98(47.1)$ & $187(52.7)$ \\
\hline \multicolumn{4}{|l|}{ 6. Hospital location by Thailand region, $n(\%)$} \\
\hline - Northeastern & $178(31.6)$ & $61(29.3)$ & $117(33.0)$ \\
\hline - Northern & $105(18.7)$ & 39 (18.8) & $66(18.6)$ \\
\hline - Southern & $104(18.5)$ & $44(21.2)$ & $60(16.9)$ \\
\hline - Eastern & $71(12.6)$ & $25(12.0)$ & $46(13.0)$ \\
\hline - Central & $105(18.7)$ & 39 (18.8) & $66(18.6)$ \\
\hline \multicolumn{4}{|l|}{ 7. Disease group, $n(\%)$} \\
\hline - Cardiovascular disease & $125(22.2)$ & $66(31.7)^{*}$ & $59(16.6)^{*}$ \\
\hline - Infectious disease & $81(14.4)$ & $16(7.7)^{* *}$ & $65(18.3)^{* *}$ \\
\hline - Cancer disease & $80(14.2)$ & $51(24.5)^{*}$ & $29(8.2)^{*}$ \\
\hline - Gastrointestinal disease & $77(13.7)$ & $27(13.0)$ & $50(14.1)$ \\
\hline - Pulmonary disease & $53(9.4)$ & $22(10.6)$ & $31(8.7)$ \\
\hline - Endocrine disease & $43(7.6)$ & $3(1.4)^{*}$ & $40(11.3)^{*}$ \\
\hline - External cause & $36(64.0)$ & $9(4.3)$ & $27(7.6)$ \\
\hline - Nephrology disease & $18(3.2)$ & $5(2.4)$ & $13(3.7)$ \\
\hline - Neurologic disease & $14(2.5)$ & $3(1.4)$ & $11(3.1)$ \\
\hline - Musculoskeletal and rheumatologic disease & $10(1.8)$ & $1(0.5)$ & $9(2.5)$ \\
\hline - Unknown cause of death & $8(2.3)$ & $0(0)$ & $8(2.3)$ \\
\hline - Other & $18(3.2)$ & $5(2.4)$ & $13(3.7)$ \\
\hline
\end{tabular}

Categorical variable; number (percent), continuous normally-distributed variable; mean \pm standard deviation. Significant differences across correct and incorrect death certificate categories were identified for normally distributed continuous variables by t-test,

Abbreviations: $N$ Number, \% Percent, COD Cause of death, SD Standard deviation, yr. Year

$p$-value $<0.05$ indicates statistical significance; ${ }^{*} p<0.001 ;{ }^{* *} p=0.001$ 
performed using SPSS Statistics version 13.0 (SPSS, Inc., Chicago, IL, USA). For all analyses, a $p$-value of less than 0.05 was considered statistically significant.

\section{Results}

\section{Medical records and DCs}

In total, 622 medical records and corresponding DCs were obtained from 14 provincial general hospitals in Thailand. Of those, 59 medical records and DCs were excluded, because certain aspects of those records were inaccessible or incomplete. In the end, 563 medical records and corresponding DCs were enrolled and included in the final analysis. The mean age of deceased patients was $58.0 \pm$ 21.5 years and $45.7 \%$ of them were female. The predominant cause of death (125 patients, 22.2\%) was cardiovascular disease. Only $36.9 \%(n=208)$ of DCs were correct for both identification of the events that led to the patient's death and COD coding. Common mistakes found on incorrectly completed DCs included incorrect sequence of events leading to death (32.4\%), mode of death use (26.2\%), nonspecific cause of death (25.7\%), linkage errors (22.3\%), incorrect COD recorded in the comorbidity section (13.9\%), incomplete diagnosis (7.1\%), no COD on the DC (6.6\%), errors in the Thai translation (6.4\%), and trivial condition (0.7\%). In addition, there were errors on the DCs concerning the leading groups of diseases, such as endocrine diseases (93.0\%), musculoskeletal and rheumatologic disease (90.0\%), infectious diseases (80.2\%), neurological diseases (78.6\%), and external causes $(75.0 \%)$. However, $31.7 \%$ of the correctly completed DCs reported cardiovascular disease and 24.5\% reported cancer; whereas, only $16.6 \%$ of DCs with errors reported cardiovascular disease and $8.2 \%$ reported cancer. The odds ratio (OR) for cardiovascular disease in the correctly completed DCs was 2.3 (95\% confidence interval [CI]: 1.63.5; $p<0.001$ ), and for cancer the OR was 3.7 (95\% CI: $2.2-$ $6.0 ; p<0.001)$. In contrast, $18.3 \%$ of the DCs with errors reported infectious diseases and $11.3 \%$ reported endocrine diseases; whereas, only $7.7 \%$ of all correctly completed DCs reported infectious diseases (OR: 0.4, 95\% CI: 0.2-0.7; $p=$ $0.001)$ and $1.4 \%$ reported endocrine diseases (OR: 0.1, 95\% CI: $0.04-0.4 ; p<0.001)$. Death certificate characteristics compared between the correctly and incorrectly completed DC groups and odds ratio of predictors of prevalence of correctly completed DCs are shown in Tables 1 and 4.

\section{Questionnaire responses from first-year general practitioners}

One hundred eighty-nine (189) of 210 (response rate 90\%) surveys were completed and returned. Of those, 34 questionnaires were excluded because the clinical records of their deceased patients were incomplete, not available, or the questionnaires were completed by physicians who

Table 2 Characteristics of first-year general practitioners by correct and incorrect death certificate groups

\begin{tabular}{|c|c|c|c|}
\hline Characteristics & All general practitioners $(n=155)$ & Correct DC GP group $(n=47)$ & Incorrect DC GP group $(n=108)$ \\
\hline 1. Age (yr.), mean $\pm S D$ & $25.3 \pm 0.8$ & $25.2 \pm 0.7$ & $25.4 \pm 0.8$ \\
\hline 2. Female gender, $n(\%)$ & $88(56.8)$ & $23(48.9)$ & $65(60.2)$ \\
\hline 3. GPA, mean $\pm \mathrm{SD}$ & $3.2 \pm 0.3$ & $3.3 \pm 0.4^{*}$ & $3.2 \pm 0.3^{*}$ \\
\hline 4. Hospital size (beds), mean $\pm S D$ & $820.5 \pm 317.5$ & $844.6 \pm 342.1$ & $810.0 \pm 307.3$ \\
\hline \multicolumn{4}{|l|}{ 5. Workload, mean \pm SD } \\
\hline - Number of OPD patients/day & $37.2 \pm 17.8$ & $37.9 \pm 19.5$ & $36.9 \pm 17.2$ \\
\hline - Number of IPD patients/day & $32.9 \pm 18.8$ & $32.6 \pm 14.2$ & $33.0 \pm 20.4$ \\
\hline - Number of IPD patients on night duty/day & $17.9 \pm 11.4$ & $17.2 \pm 10.6$ & $18.2 \pm 11.7$ \\
\hline \multicolumn{4}{|l|}{ 6. Size of medical school graduating class, $n$ (\%) } \\
\hline - > 200 medical graduates & $56(36.2)$ & $18(38.3)$ & $38(35.2)$ \\
\hline - 101-200 medical graduates & $62(40.0)$ & $18(38.3)$ & $44(40.7)$ \\
\hline - 51-100 medical graduates & $21(13.5)$ & $4(8.5)$ & $17(15.7)$ \\
\hline - $<50$ medical graduates & $16(10.3)$ & $7(14.9)$ & $9(8.3)$ \\
\hline \multicolumn{4}{|l|}{ 7. Future plans for specialist training, $n(\%)$} \\
\hline - No future training plans & $30(19.4)$ & $8(17.0)$ & $22(20.4)$ \\
\hline $\begin{array}{l}\text { - Major field training (i.e. medicine, surgery, } \\
\text { pediatrics, obstetrics and gynecology) }\end{array}$ & $88(56.8)$ & $27(57.4)$ & $61(56.5)$ \\
\hline - Minor field training & $37(23.9)$ & $12(25.5)$ & $25(23.1)$ \\
\hline
\end{tabular}

Categorical variable; number (percent), continuous normally-distributed variable; mean \pm standard deviation. Significant differences across correct and incorrect DC GP group were identified for normally distributed continuous variables by t-test

Abbreviations: N Number, \% Percent, DC Death certificate, GP General practitioner, SD Standard deviation, yr. Year, OPD Outpatient department, IPD Inpatient department, SD Standard deviation, GPA Grade point average

$p$-value $<0.05$ indicates statistical significance; ${ }^{*} p=0.03$ 
completed a DC for less than three deceased patients enrolled in this study. The remaining 155 questionnaires were included for analysis. The mean age of physician respondents was $25.3 \pm 0.8$ years, and $56.8 \%$ were female. The mean medical school GPA was $3.2 \pm 0.3$. Just over three quarters $(76.2 \%)$ of respondents graduated from large medical schools (defined as producing more than 100 physicians per year). Of 155 physicians, 47 (30.3\%; range for each medical school: $21.4-50.0 \%$ ) were able to correctly complete more than $60 \%$ of DCs (correct DC group). The remaining 108 physician respondents (69.7\%) showed poor performance in DC completion (incorrect DC group).
Mean medical school GPA was significantly higher in the correctly completed DC group than in the incorrectly completed DC group ( $3.3 \pm 0.4$ vs. $3.2 \pm 0.3 ; p=0.03)$. The odds ratio for accuracy of DCs in participants with a high GPA (GPA $\geq 3.5$ ) was 3.5 (95\% CI: $1.5-7.9 ; p=0.003$ ). However, the other characteristics were not significant different between groups. Characteristics of first-year general practitioners by correct and incorrect death certificate groups and odds ratio of predictors of prevalence of correctly completed DCs are shown in Tables 2 and 4. Questionnaire for evaluation of cause of death summary is shown in Additional file 1.

Table 3 Clinical parameters associated with death certificates completed by first-year general practitioners

\begin{tabular}{|c|c|c|c|}
\hline Clinical parameters & $\begin{array}{l}\text { All general practitioners } \\
(n=155)\end{array}$ & $\begin{array}{l}\text { Correct DC GP group } \\
(n=47)\end{array}$ & $\begin{array}{l}\text { Incorrect DC GP group } \\
(n=108)\end{array}$ \\
\hline 1. Overall DC knowledge, $n(\%)$ & $65(41.9)$ & $21(44.7)$ & $44(40.7)$ \\
\hline $\begin{array}{l}\text { - Understands that DCs are used in public health research } \\
\text { and policy, } n(\%)\end{array}$ & $66(42.6)$ & $23(48.9)$ & $43(39.8)$ \\
\hline - Can differentiate between COD and MOD, n (\%) & $39(25.2)$ & $14(29.8)$ & $25(23.1)$ \\
\hline 2. High level of self-confidence in identifying correct underlying COD, $n(\%)$ & $41(26.5)$ & $15(31.9)$ & $26(24.1)$ \\
\hline \multicolumn{4}{|l|}{ 3. Factors influencing errors in COD, $n(\%)$} \\
\hline - Lack of appropriate knowledge & $51(32.9)$ & $15(31.9)$ & $36(33.3)$ \\
\hline - Extenuating circumstance ${ }^{a}$ & $17(11.0)$ & $3(6.4)$ & $14(13.0)$ \\
\hline - High workload & $33(21.3)$ & $7(14.9)$ & $26(24.1)$ \\
\hline - Lack of adequate data & $28(18.1)$ & $10(21.3)$ & $18(16.7)$ \\
\hline - Other/non applicable & $26(16.7)$ & $12(25.5)$ & $14(12.9)$ \\
\hline $\begin{array}{l}\text { 4. Time spent on COD determination and DC completion in medical } \\
\text { curriculum (hr), mean } \pm S D\end{array}$ & $2.1 \pm 0.9$ & $2.2 \pm 0.7$ & $1.8 \pm 0.9$ \\
\hline - Time spent on COD and DCs < 2 h, $n(\%)$ & $96(73.8)$ & $29(74.4)$ & $67(73.6)$ \\
\hline \multicolumn{4}{|l|}{ 5. COD coding experience, $n(\%)$} \\
\hline - Have experience completing DCs by themselves during medical school & $43(27.7)$ & $17(36.2)$ & $26(24.1)$ \\
\hline $\begin{array}{l}\text { - Have experience completing DCs by themselves }>5 \text { cases/month } \\
\text { after graduation }\end{array}$ & $105(67.7)$ & $33(70.2)$ & $72(66.7)$ \\
\hline 6. Established COD coding training program in work hospital, $n(\%)$ & $45(29.0)$ & $13(27.7)$ & $32(29.6)$ \\
\hline \multicolumn{4}{|l|}{ 7. Person responsible for completion of death certificates during office hours, $n(\%)$} \\
\hline - Primarily senior physicians & $16(10.4)$ & $5(10.6)$ & $11(10.3)$ \\
\hline - Primarily general practitioners & $126(81.8)$ & $38(80.9)$ & $88(82.2)$ \\
\hline - On-duty general practitioner & $3(2.0)$ & $0(0)$ & $3(2.8)$ \\
\hline - Other & $9(5.8)$ & $4(8.5)$ & $5(4.7)$ \\
\hline \multicolumn{4}{|l|}{ 8. Person responsible for completion of death certificates during after hours, $n(\%)$} \\
\hline - Primary senior physicians & $3(2.0)$ & $1(2.1)$ & $2(1.9)$ \\
\hline - Primary general practitioners & $31(20.1)$ & $16(34.0)$ & $15(14.0)$ \\
\hline - On-duty general practitioner & $112(72.7)$ & $27(57.5)$ & 85 (79.4) \\
\hline - Other & $8(5.2)$ & $3(6.4)$ & $5(4.7)$ \\
\hline
\end{tabular}

Categorical variable; number (percent), continuous normally-distributed variable; mean \pm standard deviation. Significant differences across correct and incorrect DC GP group were identified for normally distributed continuous variables by t-test

Abbreviations: $N$ Number, \% Percent, COD Cause of death, MOD Mode of death, DC Death certificate, DCs Death certificates, SD Standard deviation, GP General practitioner

$p$-value $<0.05$ indicates statistical significance; all parameters in this table were $p$ above 0.05

${ }^{a}$ An example of an extenuating circumstance would be a family member of the deceased that requests that you alter the COD in order to conceal the fact that the patient had HIV infection 


\section{Clinical parameters associated with accurately completed DCs}

In terms of physician-related factors, the mean time spent on recording COD and completing DCs in the medical school curriculum was $2.1 \pm 0.9 \mathrm{~h}$, and $73.8 \%$ of participants reported spending less than $2 \mathrm{~h}$. In addition, only $27.7 \%$ of participants had experience in completing DCs by themselves during medical school. The questionnaire responses indicated that $41.9 \%$ of participants had adequate knowledge of COD coding. Only $42.6 \%$ of respondents were aware that DCs are used as health indicators and monitoring tools for public health policy. Only $25.2 \%$ of participants could differentiate between COD and mode of death (MOD), and 26.5\% reported being confident in completing DCs. The physicians that participated in this study reported being responsible for $81.8 \%$ of COD coding on DCs during office hours, and 99.6\% of COD coding on DCs after hours. Only $10.4 \%$ of participants reported that official staff took this responsibility and provided supervision during COD coding. In addition, only $29.0 \%$ of the hospitals had established DC training courses for new doctors. Common reported factors associated with DC completion were lack of clinical knowledge (32.9\%). However, these factors did not differ between the correct DC and incorrect DC groups. Clinical parameters associated with correct death certificates completed by first-year general practitioners between groups and odds ratio of predictors of prevalence of correctly completed DCs are presented in Tables 3 and 4.

\section{Discussions}

Unreliable COD data can contribute to misleading appraisals of research and poor implementation of health-related activity. Therefore, the evaluation of DC completion accuracy rates, error patterns, and relevant influencing factors is necessary to improve these data. To our knowledge, this is the first study to document the quality of COD coding in Thai hospital-based DCs completed by first-year general practitioners. We also investigated the parameters influencing accurate DC completion of these physicians graduated from a majority of medical schools in Thailand. Only $36.9 \%$ of DCs had accurately coded COD, when compared with case data in medical records. The correct DC completion result found in this study was lower than rates reported in other countries, including Canada (67.1\%) [19], Australia (84.0\%) [20], and the UK (41.4-68.0\%) [8, 21, 22]. In

Table 4 Predictors of prevalence of correctly completed death certificates: Logistic regression analysis, univariate analysis

\begin{tabular}{|c|c|c|c|c|c|}
\hline Death certificate characteristics & $\begin{array}{l}\text { Unadjusted } \\
\text { OR }(95 \% \mathrm{Cl})\end{array}$ & $p$ value & GP characteristics and associated parameters. & $\begin{array}{l}\text { Unadjusted } \\
\text { OR }(95 \% \mathrm{Cl})\end{array}$ & $p$ value \\
\hline Elderly (age $\geq 60$ yr.) & $1.2(0.8-1.8)$ & 0.2 & Age & $0.8(0.5-1.3)$ & 0.3 \\
\hline Female & $1.1(0.8-1.6)$ & 0.5 & Female & $0.6(0.3-1.3)$ & 0.1 \\
\hline Hospital Sizes & & & Medical School Sizes & & \\
\hline - 400-700 beds & Reference & & - > 200 graduates/ year & Reference & \\
\hline - 701-1000 beds & $1.1(0.7-1.7)$ & 0.6 & - 101-200 graduates/ year & $0.9(0.4-1.9)$ & 0.7 \\
\hline - More than 1000 & $1.4(0.9-2.0)$ & 0.1 & - 51-100 graduates/ year & $0.5(0.2-1.7)$ & 0.2 \\
\hline COD disease groups & & & - $\leq 50$ graduates/ year & $1.6(0.5-5.1)$ & 0.3 \\
\hline - Cardiovascular disease & $2.3(1.6-3.5)$ & $<0.001$ & Future plans for specialist training & & \\
\hline - Infectious disease & $0.4(0.2-0.7)$ & 0.001 & - Specialist training plans & $1.3(0.5-3.1)$ & 0.6 \\
\hline - Cancer group & $3.7(2.2-6.0)$ & $<0.001$ & GPA Group & & \\
\hline - Gastrointestinal disease & $0.9(0.6-1.5)$ & 0.7 & - $\mathrm{GPA} \geq 3.5$ & $3.5(1.5-7.9)$ & 0.003 \\
\hline - Pulmonary disease & $1.2(0.7-2.2)$ & 0.4 & Time spent during medical curriculum & & \\
\hline - Endocrine disease & $0.1(0.04-0.4)$ & $<0.001$ & - Time spent $\geq 2 \mathrm{~h}$ & $1.0(0.4-2.3)$ & 0.9 \\
\hline - External cause & $0.6(0.3-1.2)$ & 0.1 & COD coding experience & & \\
\hline - Nephrology disease & $0.7(0.2-1.8)$ & 0.4 & $\begin{array}{l}\text { - Have experience in completing DCs by } \\
\text { themselves during medical school }\end{array}$ & $1.8(0.9-3.8)$ & 0.1 \\
\hline - Neurologic disease & $0.5(0.1-1.7)$ & 0.2 & $\begin{array}{l}\text { - Have experience completing DCs by } \\
\text { themselves }>5 \text { cases/month after graduation }\end{array}$ & $1.2(0.6-2.5)$ & 0.6 \\
\hline - Musculoskeletal and rheumatologic disease & $0.2(0.02-1.5)$ & 0.07 & $\begin{array}{l}\text { - Established COD coding training program in } \\
\text { work hospital }\end{array}$ & $0.9(0.4-1.9)$ & 0.8 \\
\hline - Unknown cause of death/ Other & $0.4(0.2-1.1)$ & 0.05 & $\begin{array}{l}\text { Understands that DCs are used in public health } \\
\text { research and policy }\end{array}$ & $1.5(0.7-2.9)$ & 0.2 \\
\hline
\end{tabular}

Abbreviations: $D C s$ Death certificates, OR Odds ratio, $C I$ Confidence interval, $C O D$ Cause of death, DC Death certificate, DCs Death certificates, GP General practitioner, GPA Grade point average, yr. year 
addition, only $30.3 \%$ of the participating first-year physicians demonstrated good performance in DC completion. A previous study in the US [23] found that $23.0 \%$ of DCs completed by physicians were of poor overall quality. Overall, we found higher rates of common COD coding error patterns than were found in a previous US study [17], including incorrect order (32.4\% vs. 3.5\%), mode of death $(26.2 \%$ vs. $4.4 \%)$, nonspecific COD $(25.7 \%$ vs. $14.8 \%)$, and incorrectly completed DCs (13.9\% vs. $6.5 \%)$, all respectively. However, the US study was conducted in a suburban community in Broward County, Florida, and deceased patient medical records were not assessed. We found that the COD most commonly coded appropriately was malignancy of any type, followed by cardiovascular disease; whereas, accuracy of DC completion was low for endocrine and infectious diseases. This finding was consistent with two previous studies [14, 24].

Previous research in various countries attributed the validity of DCs to a number of factors relating to quality of undergraduate and postgraduate training [25], patient characteristics (age, sex) and disease responsible for the patient's death [26], type and size of hospital, and legislation governing death certification [25]. In the present study, we found that only 21.4 to $50.0 \%$ of students who graduated from each Thai medical school demonstrated good performance on DC completion. A higher GPA was the only physician-specific factor associated with the accuracy of DC completion. Although other relevant factors were not significantly different between GPs who completed DCs incorrectly and those who completed them correctly, we found that little training and little coding experience was reported by almost all students. Time spent learning about and gaining experience in DCs in the medical curriculum was low, and there was a lack of support systems or coaching in accurate COD coding. In addition, less than half of the first-year physicians reported having adequate knowledge, awareness, and self-confidence about COD coding. Correspondingly, correct methods for DC completion were briefly encountered in medical school, but studies that reviewed DC accuracy [24, 27] reported a significant need for more education. These indicate a need for more training and a more concerted effort to heighten the awareness of physicians regarding the importance of COD determination, and DC completion and coding in Thailand. DC-related skill improvement interventions have included a training package [25], workshops [28], professional development activities, and published materials [29] were required. Lastly, a recent systematic review [30] confirmed that education, especially in an interactive format, and feedback for certifiers of death should be recognized as the principal requirement for high-quality mortality statistics.

\section{Conclusions}

Although DC and COD data are used worldwide for epidemiology, research, and public health policy, the results of the present study reveal some inaccuracy in death-related documents completed by first-year general practitioners in Thailand. Moreover, this is the first study to document gaps in DC accuracy and the factors that influence DC accuracy among physicians, in terms of their understanding of death certification based on clinical assessment of medical records. In Thailand, this is most likely due to a lack of adequate training in the medical school curriculum and a lack of workplace-based support and coaching in provincial general hospitals. Accordingly, proven education, system-related support, and additional training interventions to improve the accuracy of DC completion are needed.

\section{Additional file}

Additional file 1: Questionnaire for evaluation of cause of death summary. (DOCX $20 \mathrm{~kb}$ )

\section{Abbreviations \\ Cl: Confidence interval; COD: Cause of death; DC: Death certificate; DCs: Death certificates; GP: General practitioner; GPA: Grade point average; GPs: General practitioners; OR: Odds ratio; SD: Standard deviation}

\section{Acknowledgements}

The authors gratefully acknowledge Associate Professor Denla Pandejpong for advice on research methodology and scientific support, Suthipol Udompunturak for assistance with statistical analysis, and Wayuda Muangkaew for assistance with data collection.

\section{Funding}

This study was supported by a grant from the Siriraj Research Development Fund, Faculty of Medicine Siriraj Hospital, Mahidol University, Bangkok, Thailand.

\section{Availability of data and materials}

The dataset supporting the conclusions of this article is included within the article. Questionnaire for evaluation of cause of death summary is attached as the additional file 1.

\section{Authors' contributions}

CW served as principle investigator and was responsible for the conception of the study, data collection and analysis, and drafting of the majority of the manuscript. PR assisted with data collection and analysis. PP and CC worked closely with CW on developing the concept of the study, interpreting the results, and reviewing drafts of the manuscript. WS served as study leader, collected and analyzed data, critically reviewed the manuscript, and drafted the analysis report. All authors read and approved the final manuscript.

\section{Ethics approval and consent to participate}

The present study was approved by the Siriraj Institutional Review Board, and all physicians gave their written informed consent to participate.

\section{Consent for publication}

Not applicable

\section{Competing interests}

The authors declare that they have no competing interests. 


\section{Publisher's Note}

Springer Nature remains neutral with regard to jurisdictional claims in published maps and institutional affiliations.

\section{Author details}

'Division of Ambulatory Medicine, Department of Medicine, Faculty of Medicine Siriraj Hospital, Mahidol University, 2 Wanglang Road, Bangkoknoi, Bangkok 10700, Thailand. ${ }^{2}$ Department of Medicine, Faculty of Medicine Siriraj Hospital, Mahidol University, 2 Wanglang Road, Bangkoknoi, Bangkok 10700, Thailand.

Received: 26 November 2015 Accepted: 11 June 2018

Published online: 20 June 2018

\section{References}

1. Swift B, West K. Death certification: an audit of practice entering the $21 \mathrm{st}$ century. J Clin Pathol. 2002;55(4):275-9.

2. Kelly SA, Gradwell E. The teaching of death certification. J Clin Pathol. 1992; 45(10):942-3.

3. Villar J, Perez-Mendez L. Evaluating an educational intervention to improve the accuracy of death certification among trainees from various specialties. BMC Health Serv Res. 2007;7:183.

4. Haque AS, Shamim K, Siddiqui NH, Irfan M, Khan JA. Death certificate completion skills of hospital physicians in a developing country. BMC Health Serv Res. 2013;13:205.

5. Eriksson A, Stenlund H, Ahlm K, Boman K, Bygren LO, Johansson LA Olofsson BO, Wall S, Weinehall L. Accuracy of death certificates of cardiovascular disease in a community intervention in Sweden. Scand J Public Health. 2013;41(8):883-9.

6. Leadbeatter S. Semantics of death certification. J R Coll Physicians Lond. 1986;20(2):129-32.

7. Fernando R. Medical certification of cause of death in the general hospital, Colombo. Ceylon Med J. 1990;35(2):71-4.

8. Jordan JM, Bass MJ. Errors in death certificate completion in a teaching hospital. Clin Invest Med. 1993;16(4):249-55.

9. Slater DN. Certifying the cause of death: an audit of wording inaccuracies. J Clin Pathol. 1993:46(3):232-4.

10. Benavides FG, Bolumar F, Peris R. Quality of death certificates in Valencia, Spain. Am J Public Health. 1989;79(10):1352-4.

11. Lahti RA, Penttila A. The validity of death certificates. Routine validation of death certification and its effects on mortality statistics. Forensic Sci Int. 2001;115(1-2):15-32.

12. Shojania KG, Burton EC, McDonald KM, Goldman L. Changes in rates of autopsy-detected diagnostic errors over time: a systematic review. JAMA. 2003;289(21):2849-56.

13. Porapakkham Y, Rao C, Pattaraarchachai J, Polprasert W, Vos T, Adair T, Lopez AD. Estimated causes of death in Thailand, 2005. Implications for health policy. Popul Health Metrics. 2010;8:14

14. Hernandez B, Ramirez-Villalobos D, Romero M, Gomez S, Atkinson C, Lozano $\mathrm{R}$. Assessing quality of medical death certification. Concordance between gold standard diagnosis and underlying cause of death in selected Mexican hospitals. Popul Health Metrics. 2011;9:38.

15. Mathers CD, Fat DM, Inoue M, Rao C, Lopez AD. Counting the dead and what they died from: an assessment of the global status of cause of death data. Bull World Health Organ. 2005;83(3):171-7.

16. Rukumnuaykit P. Mortality and causes of death in Thailand: evidence from the survey of population change and death registration. Asia-Pac Popul J. 2006;21(2):67-84.

17. Cambridge B, Cina SJ. The accuracy of death certificate completion in a suburban community. Am J Forensic Med Pathol. 2010;31(3):232-5.

18. World Health Organization. Medical certification of cause of death; instructions for physicians on use of international form of medical certificate of cause of death. Bull World Health Org Suppl. 1952, 3:1-20.

19. Myers KA, Farquhar DR. Improving the accuracy of death certification. CMAJ. 1998;158(10):1317-23.

20. Weeramanthri T, Beresford B. Death certification in Western Australiaclassification of major errors in certificate completion. Aust J Public Health. 1992;16(4):431-4.

21. Katsakiori PF, Panagiotopoulou EC, Sakellaropoulos GC, Papazafiropoulou A, Kardara M. Errors in death certificates in a rural area of Greece. Rural Remote Health. 2007;7(4):822.
22. Selinger CP, Ellis RA, Harrington MG. A good death certificate: improved performance by simple educational measures. Postgrad Med J. 2007;83(978): 285-6.

23. Lakkireddy DR, Gowda MS, Murray CW, Basarakodu KR, Vacek JL. Death certificate completion: how well are physicians trained and are cardiovascular causes overstated? Am J Med. 2004;117(7):492-8.

24. Ansary LA, Esmaeil SA, Adi YA. Causes of death certification of adults. An exploratory cross-sectional study at a university hospital in Riyadh, Saudi Arabia. Annals of Saudi medicine. 2012;32(6):615-22

25. Crowcroft N, Majeed A. Improving the certification of death and the usefulness of routine mortality statistics. Clin Med. 2001;1(2):122-5.

26. Battle RM, Pathak D, Humble CG, Key CR, Vanatta PR, Hill RB, Anderson RE. Factors influencing discrepancies between premortem and postmortem diagnoses. JAMA. 1987;258(3):339-44.

27. Maudsley G, Williams EMI. Death certification by house officers and general practitioners — practice and performance. J Public Health. 1993;15(2):192-201.

28. Pain CH, Aylin P, Taub NA, Botha JL. Death certification: production and evaluation of a training video. Med Educ. 1996;30(6):434-9.

29. Kircher T, Anderson RE. Cause of death. Proper completion of the death certificate. JAMA. 1987:258(3):349-52.

30. Aung E, Rao C, Walker S. Teaching cause-of-death certification: lessons from international experience. Postgrad Med J. 2010;86(1013):143-52.

\section{Ready to submit your research? Choose BMC and benefit from:}

- fast, convenient online submission

- thorough peer review by experienced researchers in your field

- rapid publication on acceptance

- support for research data, including large and complex data types

- gold Open Access which fosters wider collaboration and increased citations

- maximum visibility for your research: over $100 \mathrm{M}$ website views per year

At BMC, research is always in progress.

Learn more biomedcentral.com/submissions 